\title{
ESTUDIO DE LA EVOLUCIÓN DE RÉGIMEN HIDROLÓGICO EN ZONAS HÚMEDAS DRENADAS: LOS HUMEDALES DEL CAÑIZAR (PROVINCIA DE TERUEL, ESPAÑA)
}

\author{
J.C. Rubio Dobón y J. del Valle Melendo \\ Dpto. de Geografía y Ordenación del Territorio \\ Universidad de Zaragoza
}

\section{RESUMEN}

En el Sur de Aragón se situaban dos extensos humedales ya desaparecidos desde hace varios siglos debido a los drenajes realizados por el hombre. El mayor de ellos era la laguna del Cañizar de Villarquemado. Con sus $11,3 \mathrm{~km}^{2}$ de superficie era uno de los grandes humedales interiores de la península Ibérica. El segundo, el área de encharcamiento del Cañizar de Alba, presentaba una superficie mucho menor, en torno a $1 \mathrm{~km}^{2}$. Actualmente ambas zonas húmedas han desaparecido y sus lechos han sido intensamente transformados para uso agrícola. Dado que no existe información cuantitativa sobre su funcionamiento hidrológico en el pasado, éste se ha deducido a partir de las referencias históricas existentes respecto al clima de la zona y las principales infraestructuras hidráulicas realizadas para su drenaje. De esta forma se han deducido las principales etapas en su evolución hidrológica desde la época romana.

Palabras clave: hidrología, evolución climática, obras hidráulicas, humedales del Cañizar, Teruel.

\begin{abstract}
In the southern of Aragón there were two wetlands nowadays disappeared. The biggest one was the Cañizar of Villarquemado lake. With an area of $11.3 \mathrm{sq} \mathrm{km}$, it was one of the largest freshwater wetlands of the Iberian Peninsula. The second one, the Cañizar floodplain of Alba, has a smaller surface area of about $1 \mathrm{sq} \mathrm{km}$. Nowadays, both humid areas do not exist and its beds has been used for agricultural activity. Unfortunately, there are no quantitative data about the hydrological regime of wetlands in the past. However, the study of the historical references about local climate and drainage works has allowed to characterize the wetlands hydrology since roman age.
\end{abstract}

Key words: hidrology, climatic evolution, Cañizar wetlands, hidraulic works, Teruel. 


\section{INTRODUCCIÓN}

En España numerosos humedales han desaparecido como consecuencia de las políticas de desecación llevadas a cabo a lo largo de los últimos siglos (fundamentalmente a partir del XVIII). Dichas políticas se basaban en la necesidad de buscar nuevas tierras de cultivo, la puesta en regadío de la mayor superficie posible y la lucha contra enfermedades como el paludismo, relacionadas con estos medios palustres. No obstante mostraban un completo desconocimiento de los valores ambientales de los humedales y de su importante papel en el ciclo hidrológico.

En nuestros días dichas necesidades han desaparecido y la ciencia es consciente de la gran importancia que tienen dichos espacios naturales así como de su papel en el ciclo del agua y la biodiversidad. Además la sensibilidad social hacia el medio ambiente en general, y los humedales en particular, es grande, lo que explica el marcado cambio hacia políticas de conservación o incluso iniciativas de recuperación de antiguas zonas húmedas (Box, 1987).

La recuperación de humedales, entendiendo como tal todas aquellas actuaciones destinadas a recuperar su situación natural (Custodio 1995), requiere de un conocimiento previo de su comportamiento hidrológico que permita su caracterización, no solamente desde el punto de vista espacial sino también temporal (Wolf et al. 1986; Adamus 1988; Carter 1990; Beilfuss and Barzen 1994; Tai and Fong 1995; Molina 1995). Estos estudios previos constituyen una valiosa herramienta de planificación de todas aquellas actuaciones destinadas a su posible recuperación.

No obstante, el estudio de la evolución hidrológica de humedales ya desaparecidos por obras de drenaje antiguas plantea numerosos inconvenientes (Breedlove and Dennos 1983). El más importante es la ausencia de datos, tanto cualitativos como cuantitativos, sobre los diferentes aspectos de su régimen hídrico. Esto incluye entradas y salidas de agua en los humedales o las variaciones de la altura de la lámina de agua. A esta falta de información se ha de sumar la intensa transformación que han sufrido sus lechos y los cauces naturales de su entorno, que en algunos casos dificulta incluso la delimitación y caracterización del humedal (Casado and Montes 1995; Montes 1990). Este es el caso de los antiguos humedales del Cañizar, drenados para el uso agrícola de sus tierras en diferentes momentos desde la época romana y hasta el siglo XVIII.

Para el estudio de humedales como los del Cañizar cobra especial importancia el análisis de las fuentes documentales y los restos de las obras hidráulicas antiguas (White and Brake 1995). Todo ello puede proporcionar una valiosa información sobre las condiciones climáticas del pasado así como las actuaciones humanas realizadas sobre los humedales. Aunque esta información no suele ser numérica, en muchos casos si es suficiente para reproducir las características generales de su evolución hidrológica pudiéndose diferenciar distintas etapas desde un punto de vista hidrológico.

\section{SITUACIÓN DE LA ZONA DE ESTUDIO}

Los humedales del Cañizar se extendían por valle del Alto Jiloca, entre las localidades de Singra y Cella, situadas al Noroeste de la capital de la provincia de Teruel. Su cuenca hidrográfica limita al Este con la crestería de la sierra de Palomera y al Oeste las parameras de la sierra de Albarracín. El límite Norte lo forma el Alto de Singra mientras que el Sur coincide con la divisoria hidrográfica de la cuenca del Turia en el puerto de Cella (figura 1). 


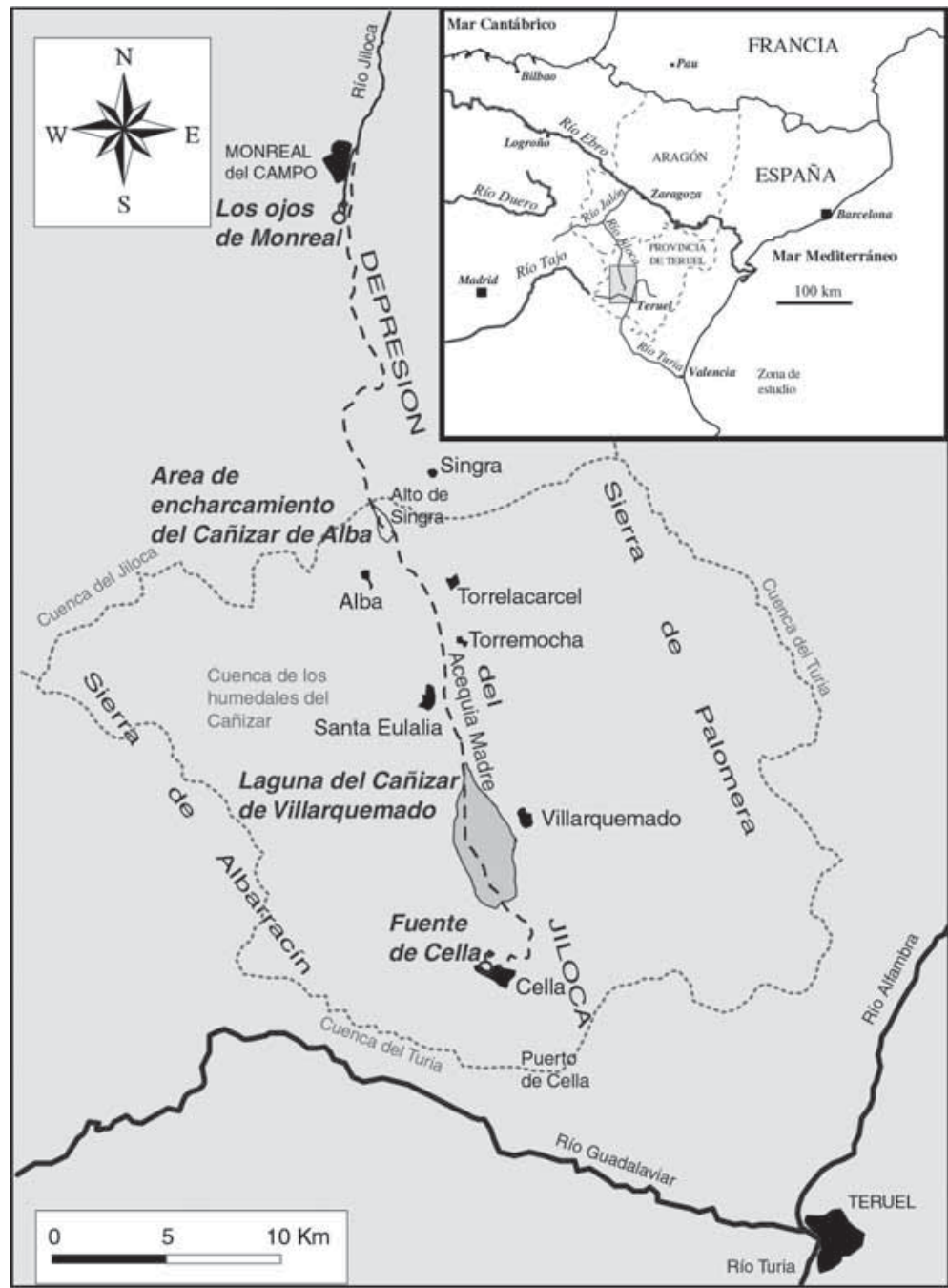

FIGURA 1. Mapa de situación.

La laguna del Cañizar de Villarquemado era el más extenso de los dos. En época de aguas altas cubría una superficie de $11,3 \mathrm{~km}^{2}$, con una profundidad máxima de $2,8 \mathrm{~m}$ y un volumen de agua almacenado de $18,78 \mathrm{hm}^{3}$. Se trataba pues de uno de los humedales esteparios de agua dulce más extensos de España. En este lago carbonatado somero de aguas dulces perennes, las descargas subterráneas eran su principal aporte de agua. Dada la escasa pendiente de su lecho y su gran superficie, es probable que la superficie inundada tuviera oscilaciones estacionales muy importantes pero sin llegar a secarse por completo, salvo durante sequías muy prolongadas e intensas.

El segundo, correspondía a la zona de encharcamiento del Cañizar de Alba. La superficie de esta zona era de aproximadamente $1 \mathrm{~km}^{2}$ (Rubio 2004). A diferencia del anterior se trataba 
de una zona de encharcamiento en la que sólo había una lámina de agua poco profunda tras periodos de fuertes lluvias o durante periodos muy húmedos. La principal entrada de agua era la escorrentía superficial, aunque con aportes subterráneos en su extremo Sur. Al Norte su lecho constituía una zona de infiltración hacia el acuífero infrayacente.

Ambos humedales han sido drenados sistemáticamente a lo largo de siglos hasta el punto de que en la actualidad se ha olvidado su existencia y su canal de drenaje, denominado popularmente como Acequia Madre, a pasado a considerarse como un tramo más del río Jiloca. La Acequia Madre tiene una longitud total de $45 \mathrm{~km}$ (Rubio 2002). A este canal principal de drenaje confluyen numerosos drenes, acequias de riego y ramblas. Atraviesa la zona de estudio de Sur a Norte desde la localidad de Cella hasta el Alto de Singra, por donde la abandona camino del caudaloso manantial los Ojos de Monreal. En este lugar desemboca en el verdadero cauce natural del río Jiloca (Rubio et al. 2003), afluente del río Jalón que a su vez es tributario del Ebro por su margen derecha.

\section{CARACTERIZACIÓN CLIMÁTICA Y RÉGIMEN HÍDRICO}

La cuenca de los humedales del Cañizar presenta un clima mediterráneo continentalizado con una precipitación media anual (Tabla 1) que supera ligeramente los $400 \mathrm{~mm}$ en Sta. Eulalia (418 mm/año), aumentando algo en los márgenes del valle (figura 2) y disminuyendo en el extremo meridional (Cella: $385 \mathrm{~mm} / \mathrm{año}$ ). En la figura 3 se puede ver la evolución de la precipitación media anual y la desviación anual de la media móvil (5 años) respecto a la precipitación media según los datos registrados en Sta. Eulalia.

Esta escasez se explica por su localización interior y la presencia de sierras ibéricas en su perímetro. Ambos hechos dificultan la llegada de masas de aire húmedo y frentes que aporten precipitación. Las perturbaciones de origen atlántico que vienen desde el NO llegan muy desgastadas, mientras las sierras de Gúdar - Maestrazgo frenan las masas húmedas de procedencia mediterránea. Por su parte, los temporales del SO se ven obligados a atravesar casi toda la península y dejan abundantes precipitaciones en el sector occidental del Sistema Ibérico, pero cuando alcanzan las tierras del Jiloca también han sufrido un fuerte proceso de desgaste reforzado por el conjunto montañoso de Sierras de Albarracín, Montes Universales y Sierra Menera, que provoca un efecto de «sombra pluviométrica» (del Valle 1993).

Tabla 1

DATOS CLIMÁTICOS BÁSICOS DE DOS OBSERVATORIOS DE LA ZONA.

\begin{tabular}{|c|c|c|c|c|c|c|c|c|c|c|c|c|c|c|}
\hline & & $\mathbf{E}$ & $\mathbf{F b}$ & $\mathbf{M z}$ & $\mathbf{A b}$ & $\mathbf{M y}$ & $\mathbf{J n}$ & $\mathbf{J l}$ & $\mathbf{A g}$ & $\mathbf{S}$ & $\mathbf{0}$ & $\mathbf{N}$ & $\mathbf{D}$ & Año \\
\hline \multirow{4}{*}{$\begin{array}{c}\text { Santa } \\
\text { Eulalia }\end{array}$} & $\mathbf{T}$ & 7,5 & 9,4 & 13,2 & 16,2 & 21,4 & 26 & 29,9 & 28,7 & 24 & 17,3 & 11,6 & 7,8 & 17,8 \\
\cline { 2 - 16 } & $\mathbf{t m}$ & 2,4 & 3,5 & 6,3 & 9,2 & 13,8 & 17,5 & 21,2 & 20,4 & 16,6 & 11 & 6,1 & 3,1 & 10,9 \\
\cline { 2 - 16 } & $\mathbf{t}$ & $-3,1$ & $-2,6$ & 0 & 2,8 & 6,6 & 10,2 & 12,7 & 12,5 & 9,7 & 5,1 & 0,6 & $-1,6$ & 4,4 \\
\cline { 2 - 15 } & $\mathbf{P}$ & 19,1 & 21 & 27,3 & 35,8 & 63,3 & 57,2 & 28,3 & 31,5 & 38,3 & 38,6 & 32,6 & 25,9 & 418,9 \\
\hline \multirow{2}{*}{ Cella } & $\mathbf{P}$ & 0,3 & 0,7 & 1,7 & 2,7 & 3,8 & 5,2 & 6,4 & 5,8 & 3,8 & 2 & 0,8 & 0,2 & 1021 \\
\hline
\end{tabular}

T: media de las temp. máximas. tm: temperatura media. t: media de las temp. mínimas $\left(\mathrm{C}^{\circ}\right)$. P: precipitación (mm). Etp: Evapotranspiración potencial (mm/dia) método: FAO Blaney-Criddle. Fuente: temperaturas y precipitación INM. Etp: Faci J.M., Martínez Cob (1991). 


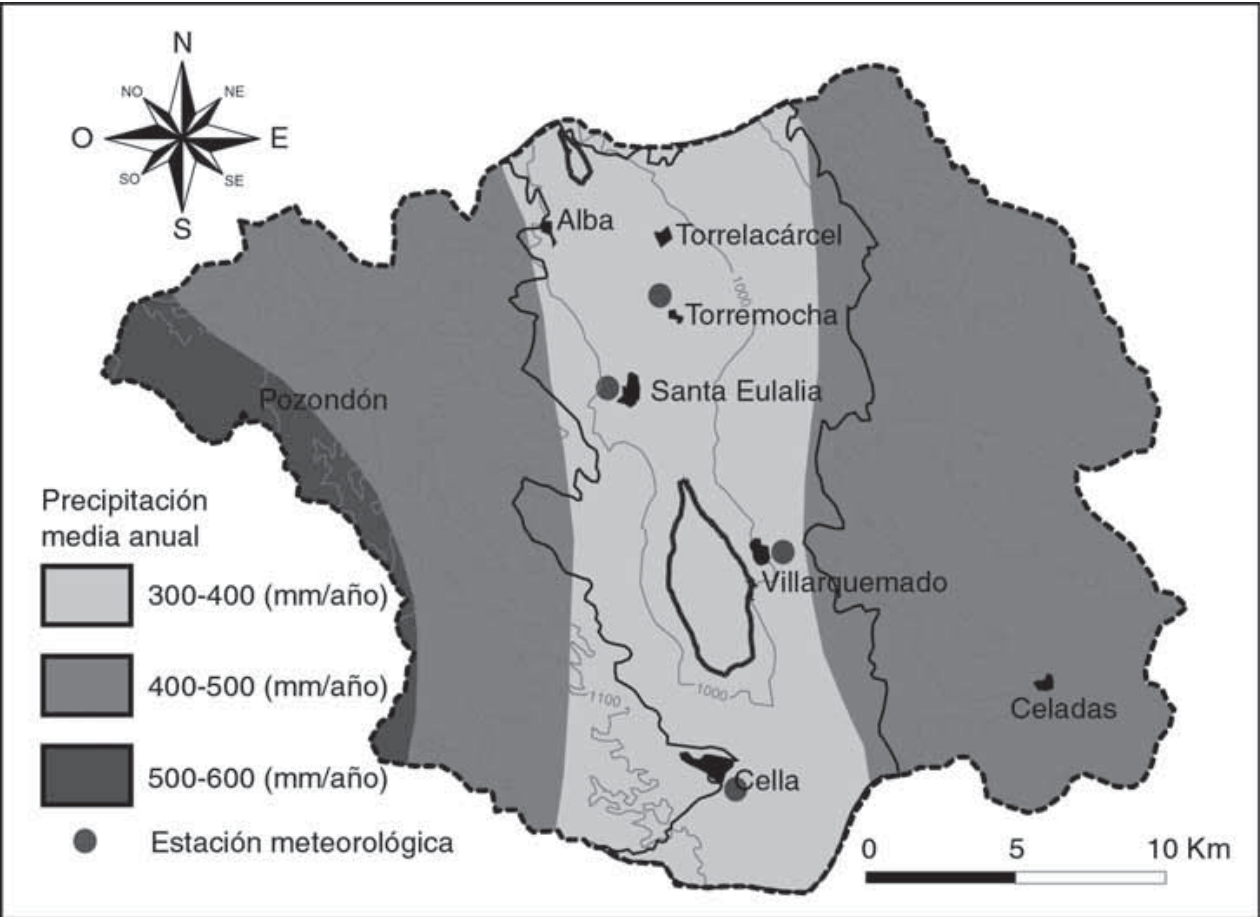

Figura 2. Mapa de precipitación media anual en el entorno de los humedales.

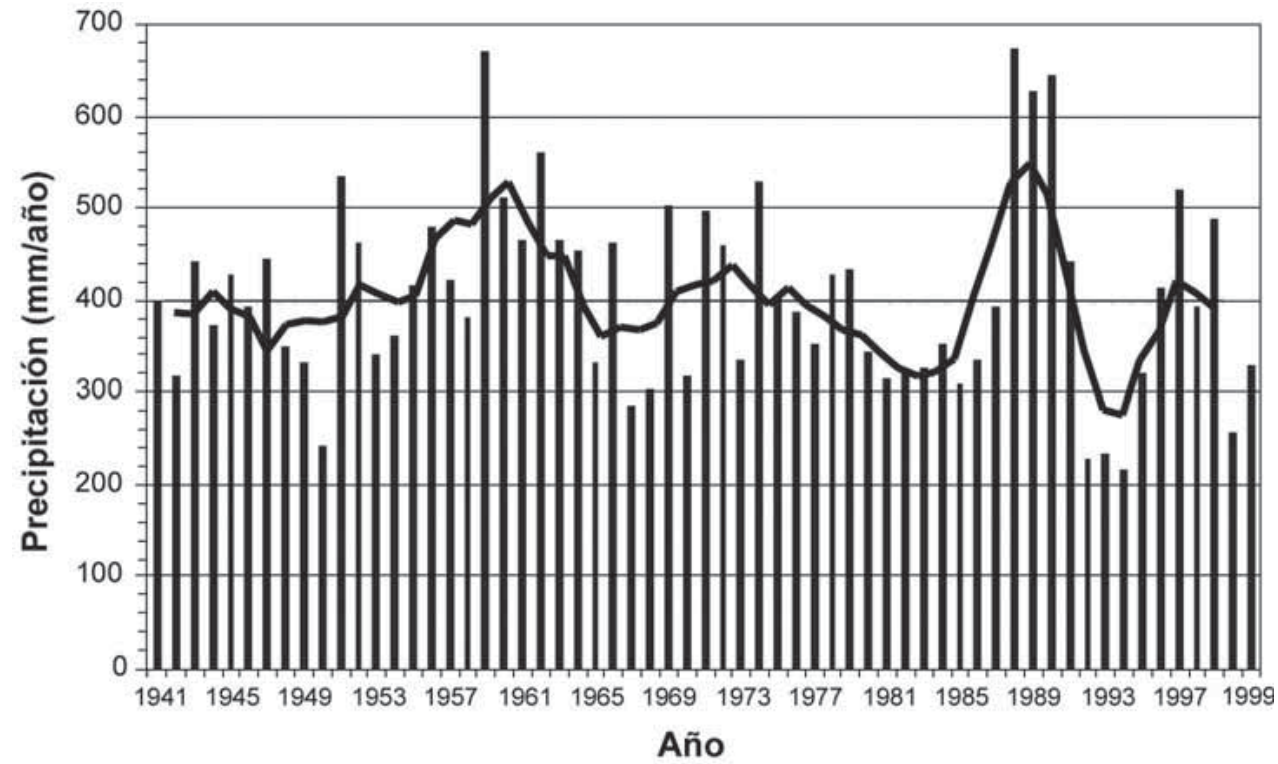

FIGURA 3. Precipitación total anual y media móvil de cinco años. 
El régimen pluviométrico muestra un máximo de finales de primavera y principios de verano. El mes más lluvioso es mayo seguido de junio (figura 4) con cantidades entre 50 y 65 $\mathrm{mm}$ tanto en Cella como en Santa Eulalia. En Otoño (octubre principalmente) se observa un máximo secundario, pero con cantidades notablemente menores. No obstante, en los meses otoñales pueden caer precipitaciones muy intensas. Es especialmente significativo el mes de septiembre de 1990, en el que en tres ocasiones (días 9, 16 y 30) se superaron los 100 $\mathrm{mm}$ de precipitación en 24 horas, los únicos registros de esta entidad en el observatorio de Santa Eulalia. Otros meses en los que las precipitaciones máximas en $24 \mathrm{~h}$ alcanzan valores elevados son mayo y agosto, con cifras ligeramente inferiores a $80 \mathrm{~mm}$ (Tabla 2).

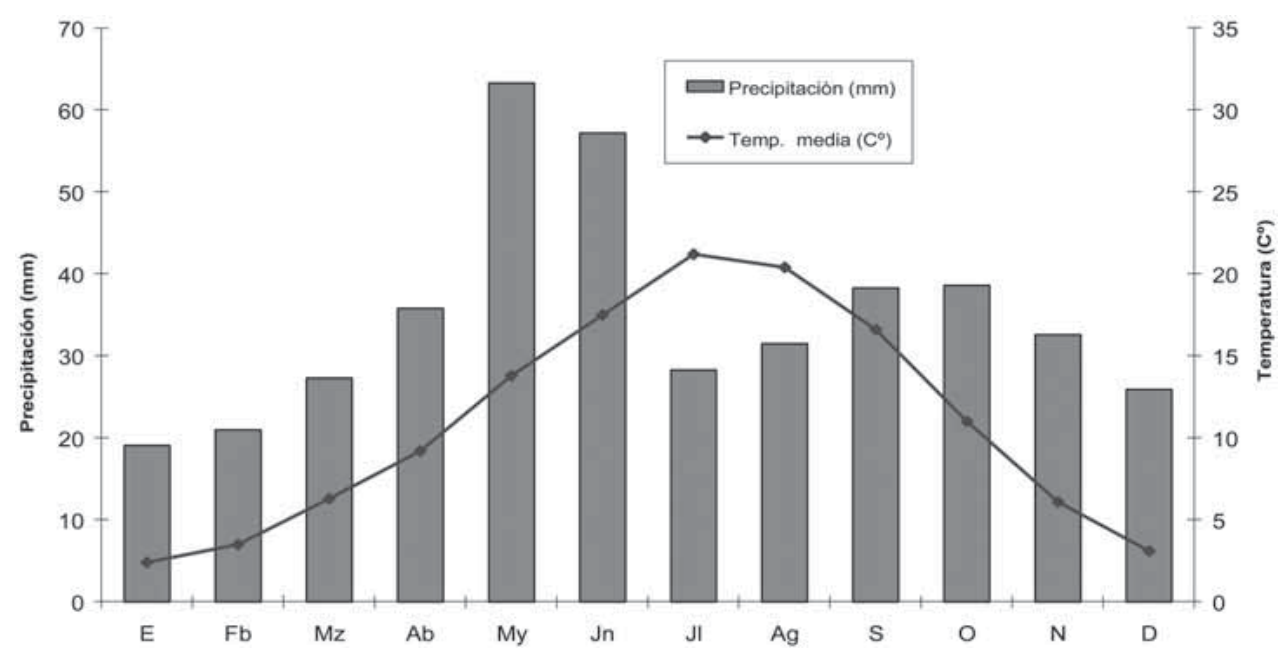

FIGURA 4.- Temperatura media y precipitación media mensual en Santa Eulalia.

Tabla 2

PRECIPITACIONES MÁXIMAS EN 24 HORAS REGISTRADAS EN SANTA EULALIA.

\begin{tabular}{|c|c|}
\hline \multicolumn{2}{|c|}{ Precipitaciones máximas diarias (mm/día) } \\
\hline Fecha & Precipitación \\
\hline 30-sep-1990 & 150 \\
\hline 9-sep-1990 & 110 \\
\hline 16-sep-1990 & 110 \\
\hline 7-sep-1984 & 93 \\
\hline 27-may-1982 & 78 \\
\hline 4-ago-1983 & 76 \\
\hline
\end{tabular}


El invierno es la estación más seca, especialmente los meses de enero y febrero, en los que la precipitación media se sitúa en torno a $20 \mathrm{~mm}$ o por debajo.

Se trata de un régimen de precipitación de influencia mediterránea, pero fuertemente continentalizado, de forma que los rasgos típicos de los regímenes mediterráneos quedan notablemente enmascarados.

Otros fenómenos dignos de señalar son las frecuentes tormentas que ocurren en la zona, especialmente en el periodo cálido (de mayo a septiembre), responsables en ocasiones de trombas de agua que pueden provocar inundaciones locales y desbordamientos de ramblas y barrancos. Estos fenómenos son los principales responsables de que la sequía estival característica de los climas mediterráneos quede tan suavizada en la zona.

Este régimen de precipitaciones se manifiesta directamente en el caudal de la Acequia Madre aguas abajo de los humedales. En la figura 5 se muestra la precipitación recogida en la estación meteorológica del Instituto Nacional de Meteorología en la localidad de Torremocha del Jiloca y el caudal registrado por la estación de aforos de la Acequia Madre situada en el cierre de la laguna del Cañizar de Villarquemado durante el año hidrológico 2002/03.

El caudal medio de la Acequia Madre en este punto fue de 268 1/s con un máximo de 1081 1/s y un mínimo de 64 1/s. El máximo corresponde al día 9 de mayo de 2003, cuatro días después de producirse la mayor precipitación diaria $(40 \mathrm{~mm})$.

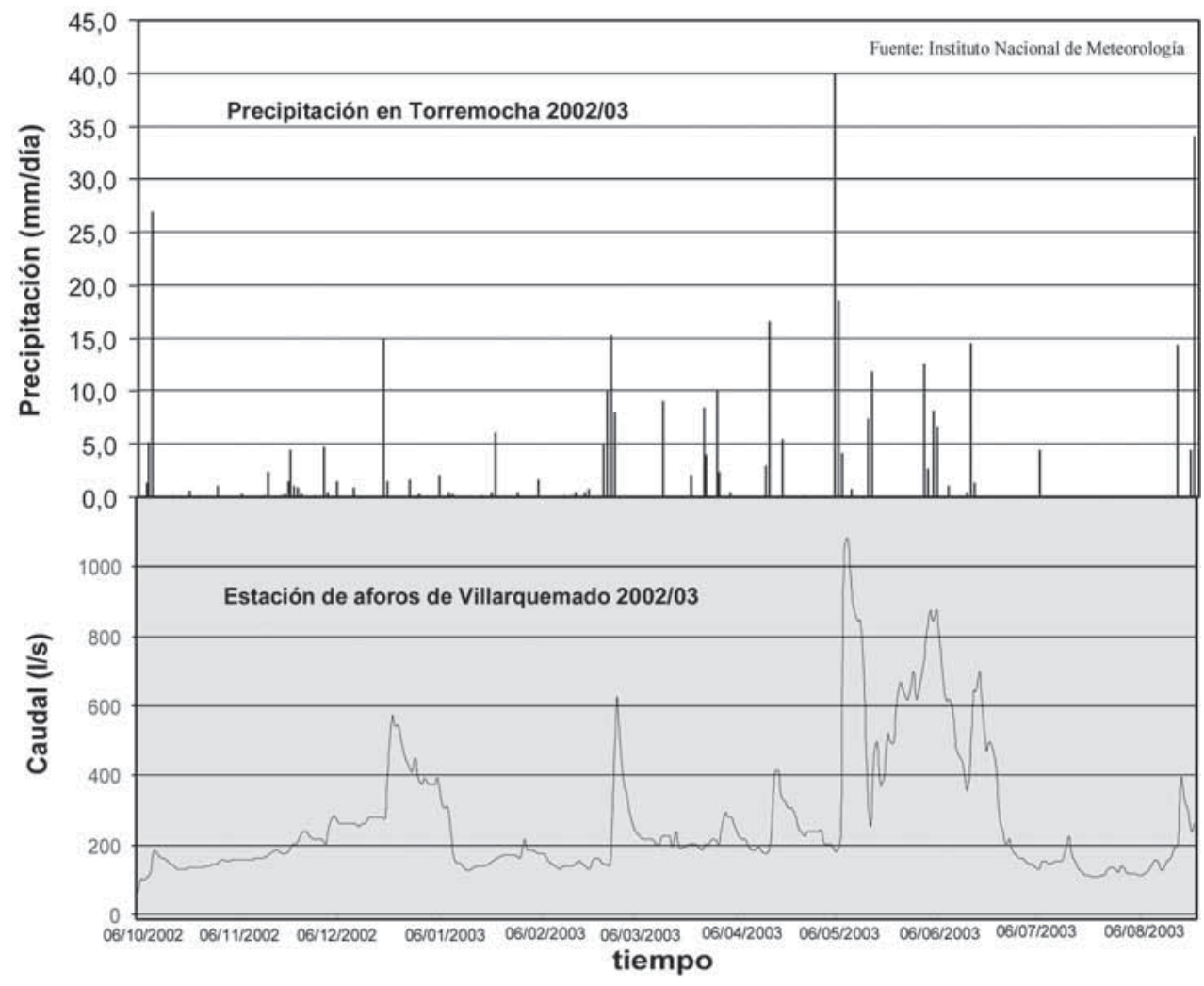

FIGURA 5. Relación precipitación - escorrentía en la Acequia Madre. 
En general, cuando las precipitaciones son de carácter regional se observa un elevado tiempo de respuesta, entre dos y cuatro días (Rubio 2004), desde que se produce la precipitación hasta que llega la punta de la crecida a la estación de aforos. Dada la escasa extensión de la cuenca, la única explicación a este fenómeno radica en el origen subterráneo del agua que recargaba a la laguna y que ahora fluye por la Acequia Madre.

\section{EL ORIGEN DE LOS HUMEDALES}

Durante el Villafranquiense y a lo largo del Cuaternario, el hundimiento de la fosa del Jiloca (Simón 1983; Hernández et al. 1985), en cuyo eje central se encuentran los humedales, ha dado lugar a la existencia de áreas endorreicas de difícil drenaje. Durante este periodo se han ido alternando etapas en las que esta zona era una cuenca endorreica con otras en los que las aguas fluían hacia la red fluvial articulada en torno al río Jiloca.

Otro factor causante del endorreísmo en la zona es la formación de abanicos aluviales que partiendo de ambos bordes de la fosa penetran hacia el interior de la cuenca (Ramírez et al. 1983) cerrando el desagüe natural de las aguas y originando también áreas endorréicas.

La zona endorréica de los humedales del Cañizar parece haber persistido a lo largo del Holoceno, si bien su morfología ha ido variando con el tiempo. En este cambio ha sido especialmente importante la evolución en el régimen de aporte de sedimentos en los abanicos aluviales que formaban el cierre topográfico de los humedales. Una mayor tasa de sedimentación dentro de los humedales respecto a la de los abanicos del cierre producía una reducción de la zona lacustre y viceversa.

En el caso del Cañizar de Alba, la baja tasa de sedimentación en el abanico aluvial que cierra su cuenca ha provocado la reducción de esta zona lacustre hasta convertirla en la zona de encharcamiento actual. Por contra, en el caso de la laguna del Cañizar de Villarquemado, los aportes hacia el abanico formado por la rambla de Villarrosano, una de las de mayor cuenca hidrográfica de la zona, permiten que la laguna no se colmate.

\section{EVOLUCIÓN HIDROLÓGICA DURANTE LA ÉPOCA ROMANA}

La evolución hidrológica de los humedales del Cañizar durante la época romana se enmarca en un contexto climático dentro del cual se pueden diferenciar dos periodos con distintas características generales (Font, 1988).

- Periodo de transición subboreal - subatlántico $(500 \mathrm{aC}-100 \mathrm{aC})$. A tenor de la escasa información disponible parece ser que a comienzos de este periodo (entre 600 y $500 \mathrm{aC}$ aprox.), el régimen climático, era más frío y con más lluvias invernales que el actual. Hay constancia de inviernos muy duros y bosques de hayas en zonas de la Cuenca mediterránea donde hoy no existen. Las noticias indican largos periodos de sequías alternados con otros de lluvias intensas, especialmente en invierno. Debido a la localización de los humedales del Cañizar, es probable que fueran las de origen mediterráneo las que los afectaran con más intensidad. También tenemos noticias de sequías, como la que se produjo en toda la región mediterránea en 427 a C. y especialmente la «Gran Seca» de 26 años (224 a 198 aC) que afectó con intensidad a toda Hispania.

- Episodio cálido romano $(100$ a $\mathrm{C}-400 \mathrm{dC})$. Es un periodo de temperaturas más suaves, veranos cálidos y secos y falta de inviernos extremados. En líneas generales, las condiciones climáticas eran similares a las actuales, pero con unos inviernos más suaves y parece ser que con un régimen de precipitación más regular en el que los periodos secos y lluviosos, aunque presentes, eran menos marcados que en el periodo anterior. Como elementos climáticos destacables, aparecen la sequía del año 75 a C o las intensas lluvias del 49 a C. 
Respecto a las actuaciones humanas sobre los humedales del Cañizar, durante esta época comienzan a realizarse cambios importantes en su entorno natural. Aunque no existe constancia de la existencia de una red de acequias o un sistema de drenes de los humedales ésto se debe más a la falta de información sobre este periodo que al hecho poco probable de que no existieran. Seguramente ya desde la dominación romana se comenzó a articular un sistema de canales y drenes cuando menos basado en el drenaje de los humedales del Cañizar.

Este podría ser el caso de la antigua red de drenaje que se extiende al Sur y Oeste de la localidad de Torremocha en torno a un cauce central denominado «río Viejo». Este conjunto de canales y drenes drenan la zona de manantiales de la fuente de Cañonda y el área de encharcamiento del Cañizar de Alba. Al comienzo de los canales se han encontrado caños artificiales que continúan por el subsuelo favoreciendo la capacidad de drenaje de los canales. Están formados por losas de piedra plana a los lados y en el techo que evitan que la galería se derrumbe. Además de los situados en el comienzo de los canales hay otros laterales que contribuyen al drenaje de la zona (figura 6).
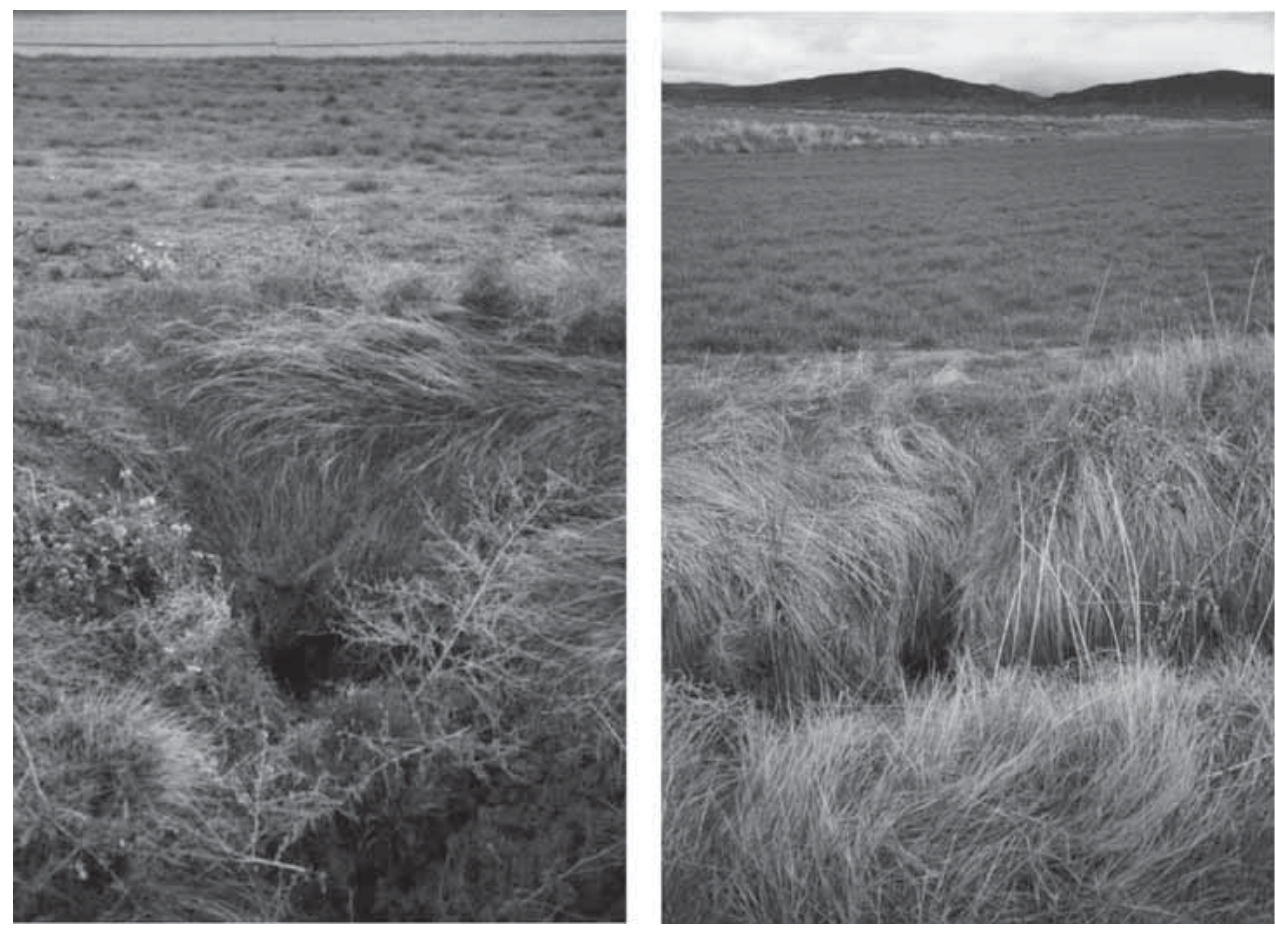

Figura 6. Drenes en el paraje de la Fuente de Cañonda.

Respecto al drenaje de la laguna del Cañizar de Villarquemado éste, si lo hubo, no debió de modificar significativamente su régimen hídrico natural. Dado el régimen hídrico de esta laguna, es muy probable que durante los periodos húmedos en la época de aguas altas el nivel de la laguna rebosase en su cierre creándose de esta forma un emisario aguas abajo hacia la zona de encharcamiento del Cañizar de Alba. 


\section{6. ÉPOCA MEDIEVAL Y MODERNA HASTA EL SIGLO XVII}

Con el alumbramiento de la Fuente de Cella (pozo artesiano de gran caudal situado junto al casco urbano de Cella), probablemente durante los primeros años tras la reconquista (finales del siglo XII), la red hidrográfica preexistente va a cambiar de forma sustancial (Deler 1995). El caudal que ésta vertía a la laguna llevó consigo la necesidad de realizar su drenaje ya que los nuevos aportes de agua debían hacer incrementar su nivel más allá de sus niveles naturales inundando tierras de cultivo que, aunque dentro del lecho de la laguna, no se solían cubrir de agua con frecuencia.

El primer drenaje de la laguna del Cañizar de Villarquemado del que se tienen referencias escritas fue la construcción de la Acequia Madre (probablemente a finales del siglo XII) al cual se sumarían otros intentos de mejora como el realizado en 1323 (Gargallo 1996). Ese año, al quedar seca la laguna del Cañizar de Villarquemado como consecuencia de la prolongada sequía, los vecinos de las aldeas ribereñas solicitaron al rey de Aragón, Jaime II, que les autorizase la venta de sus primicias para hacer frente a las obras de drenaje destinadas a poner en cultivo la superficie ganada a la laguna. Se tiene constancia de que tres años más tarde aún proseguían las labores y de que por fin cuando se reestableció el régimen pluviométrico habitual se volvió a inundar el lecho de la laguna resultando baldío todo el trabajo de drenaje realizado.

Se puede afirmar que hasta el siglo XVIII la laguna del Cañizar de Villarquemado, debido a sus cuantiosos aportes de agua y la forma de su vaso, no sufrió cambios significativos en su régimen hídrico debido a la apertura de la Acequia Madre manteniendo gran parte de su superficie y profundidad.

Todo este conjunto de actuaciones sobre los humedales del Cañizar se sitúan dentro de un contexto climático muy variable en el que se pueden diferenciar los siguientes periodos (Font, 1988):

- Episodio frío altomedieval (400 - 1000 dC). Durante el periodo del siglo V a principios del XI se sufre un periodo de intensos fríos invernales y con un régimen de lluvias mucho más irregular y extremado que durante el anterior periodo, el episodio calido romano. Se registran intensas sequías en los siglos V, VI y VIII, algunas de las cuales causaron grandes hambrunas en otras zonas de la región Mediterránea. Alternándose con las sequías hubo intervalos muy lluviosos. A finales del siglo X se generalizan los inviernos con estas características.

- Periodo cálido y húmedo bajomedieval (1000 a 1300). A lo largo del siglo XI el clima va haciéndose más suave y húmedo, con alguna sequía esporádica. En el siglo XII se generalizan las características húmedas y cálidas. No hay sequías destacables en el siglo, aunque en general los inviernos fueron secos y poco rigurosos. También durante el siglo XIII se mantienen las mismas características, pero aumenta la pluviosidad general de forma suave, con noticias frecuentes de riadas e inundaciones en otras zonas de la cuenca Mediterránea.

- Suavidad climática de finales de la edad media (siglos XIV y XV). Durante estos siglos hubo bastante actividad ciclónica en el Mediterráneo, lo que contribuye a mantener unas características cálidas y húmedas. Los periodos fríos son esporádicos y poco frecuentes, al igual que las sequías: solamente destacan las de 1323, en la que se realizó el ya mencionado intento de drenaje de la laguna de Cañizar de Villarquemado, 1333 y alguna otra esporádica. En conjunto, el siglo XIV fue lluvioso, pero menos que el XIII. Sin embargo, predominaron las situaciones del Oeste, que afectan de forma debilitada a la cuenca de los humedales del Cañizar, por lo que 
aquí no debió ser tan lluvioso como en la mitad occidental de la Península. Hay constancia de una avenida del Jiloca en 1349.

- Siglo XV. En este siglo los periodos secos fueron más largos e intensos en la segunda mitad del siglo. Alguna sequía extraordinaria ya aparece, especialmente la de fines de 1473 a fines de 1475. También aparecen algunos inviernos muy lluviosos, y hemos de destacar la fuerte actividad tormentosa del verano de 1458 y la intensa actividad ciclónica en el Mediterráneo en el periodo 1485 - 1500, con fuertes aguaceros en la cuenca de los humedales, aunque de menor intensidad que en la costa mediterránea. En conjunto la primera mitad del XV fue cálida y algo lluviosa, mientras la segunda mitad fue mucho más irregular, alternándose periodos secos y lluvias abundantes.

- Pequeña edad del hielo: siglos XVI y XVII. El siglo XVI supuso un periodo frío generalizado, algo atenuado en su primera mitad y más intenso en la segunda, en la que los extremismos térmicos y pluviométricos se generalizan. Destacan por su crudeza los inviernos del periodo 1503 - 1511 y 1529 - 1539. A partir de 1560 el frío se generaliza y se agudiza, siendo muy frecuentes los inviernos rigurosísimos por llegada de aire siberiano. En lo referente a las precipitaciones, en general el siglo fue seco. Son varias las noticias de escasez grave de agua, como la que señala que en 1504, 1515 y 1525 el molino de Fuenteseca (situado en el Alto de Singra) no se podía utilizar porque se había secado la Acequia Madre. Fue muy seco el periodo 1530 - 71 (el 1 de abril de 1556 los jóvenes de Cella acudieron en peregrinación al cercano santuario de la Fuensanta de Villel para rogar por las lluvias) y también el periodo 1580 - 89, con algún año lluvioso intercalado, como 1582, en el que la actividad tormentosa fue muy intensa en verano. También hemos de destacar los veranos de 1540-1542, 1565 y 1593 por la actividad tormentosa estival y las inundaciones de las que hay constancia en la vecina Daroca (situada $50 \mathrm{~km}$ al Norte), en 1551 y en 1575 , ambas en julio.

- Siglo XVII. Encontramos en él características similares, aunque con un régimen de lluvias algo más favorable. El siglo comenzó con un periodo de 1600 a 1620 en el que se recuperan notablemente las precipitaciones, pero se hace más seco posteriormente. Destacan las sequías de la década de los cuarenta (en 1647 el Papa recibe una súplica de los vecinos de Cella para que vuelva a llover, pues según ellos desde hacía varios años no tenían cosechas y sufrían calamidades). También entre 1680 y 1683 hay una intensa sequía, hasta el punto de que en 1683 la fuente se secó de tal forma que «no se podía coger agua sino en lo profundo de dicha fuente» (Deler, 1995). No obstante, aunque éstas fueron las condiciones generales, la actividad tormentosa estival, intensa en agosto de 1674 y 1676, contribuyó a suavizar algo las condiciones secas de la segunda mitad del siglo.

\section{SIGLOS XVIII Y XIX}

El panorama hidrológico de los humedales del Cañizar sufre un cambio radical a comienzos del siglo XVIII cuando tras las múltiples quejas y ruegos de los vecinos de Villarquemado por las enfermedades que, según éstos, causaban las aguas estancadas en la laguna del Cañizar, la Audiencia de Aragón (autoridad competente en materia de aguas) examinó la posibilidad de efectuar las obras de saneamiento del humedal y la reforma del sistema de riegos de la zona.

Tras aprobarse su realización, los trabajos de drenaje de los humedales del Cañizar y de remodelación de la red de acequias de riego comenzaron en 1729 siendo diseñados y supervisados por el ingeniero italiano Domingo Ferrari. En total, las obras duraron tres años 
con un coste total que ascendió a 13000 libras valencianas según el testimonio de Antonio de Puga, secretario de S.M. y escribano de Cámara en el Tribunal de Justicia (Deler, 1990). El resultando de estas obras fue la total desecación de la laguna del Cañizar para satisfacción de los vecinos de Villarquemado, como queda de manifiesto en el texto de las Ordenanzas del año 1742: «Se experimentaron, y vieron todas las utilidades interesales, y apetecidas por los Pueblos, asi en salud pública de sus naturales, como en la de la paz, y tranquilidad que éstos tuvieron con el logro de regar, y fertilizar sus Campos, y asegurar sus cosechas, con la conservación, y aumento de sus Ganados mayores, y menores.»

El drenaje del siglo XVIII se articula entorno a dos elementos principales. El primero de ellos es la reforma de la Acequia Madre, cauce que la atraviesa de Sur a Norte por su parte central. El segundo es la construcción de drenes dentro del lecho de la antigua laguna.

Las obras de Ferrari reestructuraron el cauce de la Acequia Madre en el cierre de los dos humedales del Cañizar. En el caso del área de encharcamiento del Cañizar de Alba su cauce se desvió y profundizó para favorecer que las aguas pudieran salvar la cota del cierre. También en la laguna del Cañizar de Villarquemado, este tramo fue sobreexcavado con el mismo fin. Otra actuación en la Acequia Madre a su paso por el lecho de esta laguna, probablemente también obra de Ferrari, fue el levantamiento de diques a ambos lados del cauce en la zona central, y más profunda, de la laguna para evitar que se volviera a inundar.

En relación a los drenes, éstos fueron excavados a ambas márgenes de la Acequia Madre con una triple función. Los situados en la margen izquierda son colectores de los abundantes manantiales existentes en la vega de Cella. A través de ellos se canaliza el agua de las descargas del acuífero (principal entrada de agua a la laguna) hacia la Acequia Madre evitando que vuelva a inundar el humedal. Otros, los situados en las partes marginales del lecho recogen el agua de los riegos realizados con las acequias que parten de la Fuente de Cella evitando que lleguen a la laguna. Por último, en la margen derecha, los situados más próximos a la Acequia Madre son simples drenes diseñados para evitar el encharcamiento natural de esta área (figura 7).

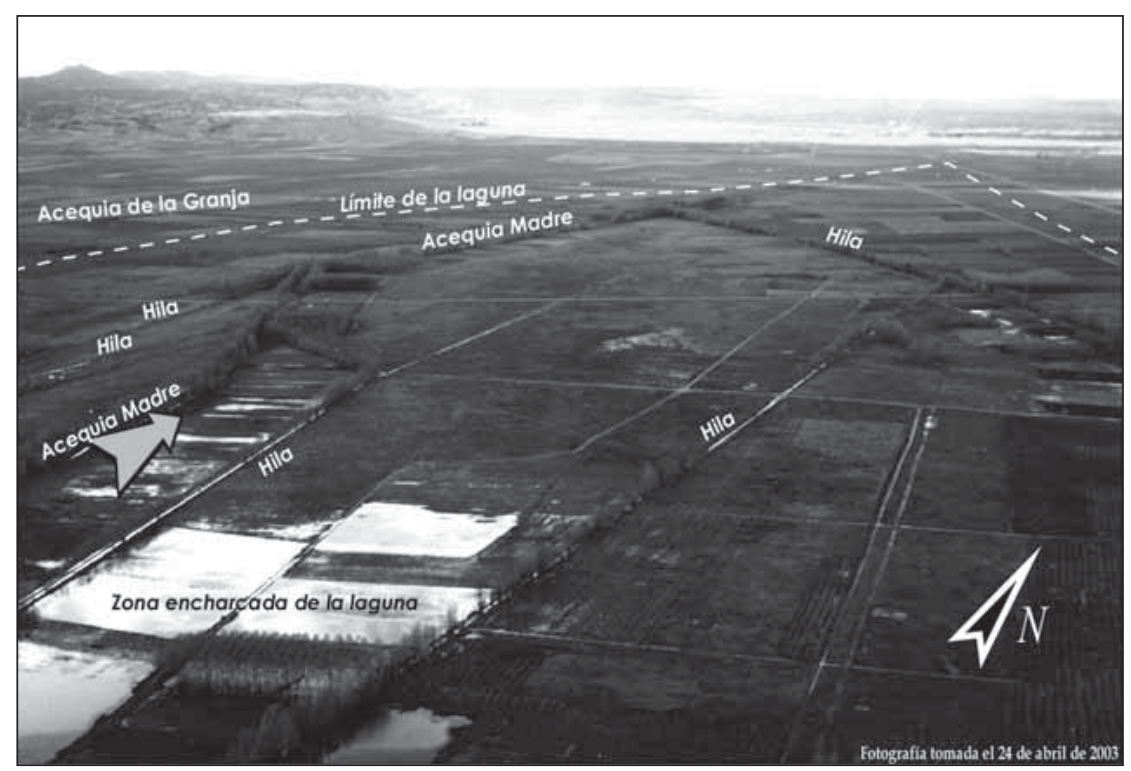

Figura 7. Vista aérea del sistema de drenajes de la laguna del Cañizar de Villarquemado. 
Las actuaciones realizadas en los humedales del Cañizar durante el siglo XVIII responden más a las nuevas ideas de la ilustración que a la necesidad de dar una respuesta a eventos climáticos ya que en este siglo no se registran periodos de largas sequías y en ningún caso tenemos constancia de que se secara la fuente de Cella o de que hubiera situaciones de calamidad por sequía. Sólo cabría destacar un descenso de las precipitaciones en el intervalo 1770-1785. Tampoco destaca ningún periodo por sus abundantes precipitaciones, solamente años sueltos. En general fue un siglo relativamente benigno, con recuperación térmica, disminución de crudos inviernos e intensas heladas y en general reducción de frecuencia de eventos climáticos extraordinarios.

Durante el siglo siguiente las actuaciones sobre los humedales se limitaron a arreglos puntuales y labores de mantenimiento de las infraestructuras hidráulicas realizadas durante el siglo XVIII sin que se tenga constancia de obras significativas en los drenajes de los humedales ni en la red principal de acequias.

No obstante, el siglo XIX fue en general más voluble que el anterior desde un punto de vista climático, con periodos fríos y cálidos, húmedos y secos bien marcados (Font, 1988). En conjunto no fue un siglo seco, aunque aparecen sequías esporádicas, en algunas de las que baja considerablemente el caudal de la fuente de Cella, pero se recupera con las lluvias de septiembre. Hemos de destacar 1872-79, con una sequía especialmente intensa en el periodo 1875-79 (que no impide la riada del Jiloca en Daroca en 1877). También se aprecian periodos de precipitaciones importantes, como 1829-31, 1852, 1881-85 o la intensa actividad tormentosa de agosto de 1894 y del trienio 1897-99, en el que se registran inundaciones por desbordamiento del Jiloca en julio, agosto y septiembre de 1887 y por el Pancrudo (afluente del Jiloca) en 1888.

\section{SIGLO XX}

El siglo XX se caracteriza por su variabilidad climática. Respecto a los periodos más lluviosos, podemos destacar 1936 (en agosto se inunda la Vega de Fuentes Claras, situada $20 \mathrm{~km}$ al Norte de la cuenca de los humedales), 1947 y el decenio 1956-65. Durante 1956 se produjeron «terribles inundaciones» en el lecho de la laguna del Cañizar de Villarquemado, lo que significa una inundación temporal del antiguo vaso de la misma. También en 1958 se produjeron inundaciones, llenándose otra vez por completo el lecho de la laguna; 1959 y 1960 fueron muy lluviosos (en 1959 se registran inundaciones en septiembre y diciembre y en 1961 en enero y diciembre), y posteriormente 1986, con tormentas excepcionales en julio, que causaron inundaciones locales en la zona. Los años de mayor actividad tormentosa estival fueron 1959, 1960 y 1963, año en el que la rambla de Celadas (vierte sus aguas en el extremo Sur de la laguna del Cañizar de Villarquemado) se desborda en julio y agosto.

Por el contrario, a lo largo del siglo las sequías han aumentado su protagonismo respecto a siglos precedentes, destacando los años 1905, 1907 (a pesar de que se registra un desbordamiento del Jiloca), 1918, 1924, 1931-32 y especialmente el periodo 1944-54, en la que el año meteorológico 44-45 fue extraordinariamente seco. Posteriormente destaca la gran sequía de los años ochenta, en la que fue especialmente duro el periodo 1982-84 y también el final de 1985 (a pesar de la sequía, se registran riadas en la zona en mayo y junio de 1982, agosto de 1983 y mayo de 1984). Vuelve a aparecer un periodo seco intenso entre 1993 y 1995. En ambos periodos secos llega a quedar completamente seca la fuente de Cella, descubriéndose los dos conductos kársticos por los que mana el agua.

A partir de la segunda mitad del siglo XX la poca seguridad del regadío tradicional con aguas superficiales debido a la sucesión de estos periodos secos, y la más que aceptable 
rentabilidad del cultivo de regadío de la remolacha, produjo en la zona un incremento espectacular en la perforación de pozos.

El resultado de esta fiebre del agua subterránea fue un descenso generalizado en los niveles del acuífero pliocuaternario debido a las extracciones de los pozos de que captaban aguas de éste. Este descenso también dio lugar a la completa desaparición de la zona de manantiales situados junto a la localidad de Torremocha y los encharcamientos ocasionales en los humedales del Cañizar, especialmente en el caso del área de encharcamiento del Cañizar de Alba y prados adyacentes, muy sensibles a los cambios en el nivel freático del acuífero pliocuaternario.

Durante estos años, comenzó un proceso autoinducido cuyo resultado final fue una crisis hídrica en el sistema acuífero pliocuaternario-humedales del Cañizar-Acequia Madre. La proliferación de pozos hacía descender el nivel freático del acuífero pliocuaternario, a su vez debido a este descenso cada vez era más difícil que circulase el agua por la red de acequias, ya que desde éstas, se infiltraba más agua hacia el acuífero. Por último, la inseguridad en la disponibilidad de agua en los regadíos tradicionales motivaba a los agricultores a realizar más pozos para asegurar las cosechas. De esta forma se cerraba un ciclo cuyo resultado fue la desecación total de los humedales del Cañizar.

El cierre de la fábrica azucarera de Santa Eulalia en 1985 vino a cambiar por completo el panorama agrícola de toda la comarca. La perdida de rentabilidad de los nuevos cultivos de regadío llevó asociado la ausencia de nuevas perforaciones y el abandono de muchos de los pozos ya existentes. A pesar de la disminución las extracciones, los niveles piezométricos continúan estando muy bajos por lo que muchos manantiales, antaño generosos en caudal, siguen secos. Tampoco por la Acequia Madre, eje del sistema de riego fluye suficiente agua para continuar con los riegos tradicionales, excepto durante años muy húmedos como el 2002/03.

\section{RESUMEN Y CONCLUSIONES}

- La recuperación de un humedal es un proceso complejo, y necesita de rigurosos estudios hidrogeológicos e históricos para identificar las intervenciones realizadas por el hombre para su transformación. Gracias a ellos es posible reconstruir el dinamismo natural de las zonas húmedas previo a ellas.

- En el caso de los humedales que nos ocupan, los datos históricos indican que, muy probablemente, los primeros proyectos desarrollaron para su transformación o desecación parcial, daten de época romana. Estos primeros drenajes no supusieron alteraciones significativas en sus características naturales ni en la extensión que ocupaban, probablemente debido a las características generalmente húmedas propias de este periodo.

- La primera obra con una clara repercusión en el drenaje de los humedales data de época medieval, posterior a la apertura de la Fuente de Cella, y se trata de la construcción de la acequia Madre. Sin embargo tampoco significó una alteración profunda, pues la laguna de Cañizar de Villarquemado no sufrió transformaciones sustanciales en su régimen hídrico hasta el siglo XVIII.

- En el siglo XVIII se desarrolla una obra de ingeniería que permite el drenaje completo de la lagunas del Cañizar. Durante este siglo las condiciones climáticas fueron en general benévolas (húmedas y sin extremismos térmicos), lo que favoreció las actividades agrarias, impulsando el drenaje de los humedales para su aprovechamiento agrícola.

- Durante la segunda mitad del siglo XX se perforan numerosos pozos para riego que han supuesto un notable descenso del nivel del acuífero que alberga los humedales, especialmente en los intensos periodos secos que se han registrado en este periodo. 
- A modo de resumen, se muestra en la figura 8 la evolución del régimen de precipitación en el entorno de los humedales y las principales actuaciones de drenaje realizadas sobre ellos.

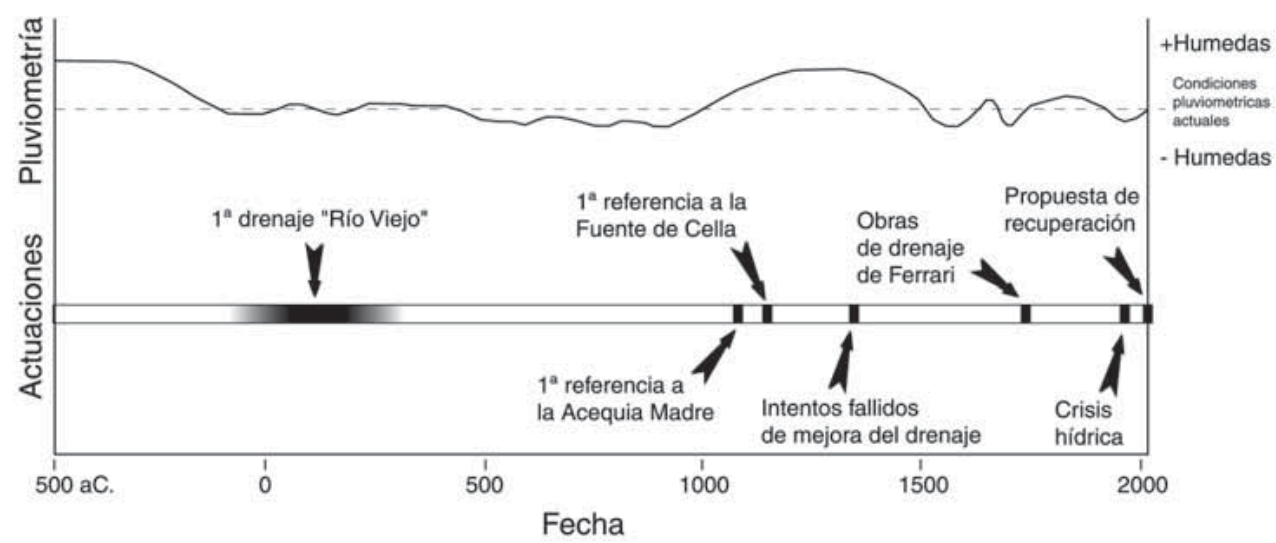

FIGURA 8. Evolución de las precipitaciones y principales intervenciones humanas en los humedales.

- El conjunto de las actuaciones antrópicas sobre los humedales del cañizar y su entorno son la causa de que actualmente se les pueda considerar como zonas húmedas ya desaparecidas, a pesar de los encharcamientos temporales que suelen presentan en periodos húmedos.

- Por último, desde finales del pasado siglo se ha producido un importante cambio en la actitud y valoración social de las zonas húmedas que explica el interés por su conservación o incluso su restauración en algunos casos. Muy recientemente se ha realizado la instalación de unos paneles informativos sobre los antiguos humedales y su estado actual, y se ha desarrollado un proyecto para estudiar la viabilidad de su posible recuperación parcial, tal y como ha ocurrido con otros humedales españoles que también habían sido desecados (lagunas de La Nava y de la Janda).

\section{AGRADECIMIENTOS}

Este artículo ha sido realizado dentro del proyecto «Estudio hidrogeológico de los humedales del Alto Jiloca» (No 221-174.), financiado por la Universidad de Zaragoza.

Agradecemos también la colaboración del Dr. D. Pablo Coloma López por su contribución a este estudio.

\section{BIBLIOGRAFÍA}

ADAMUS, P.R. (1988): Criteria for created or restored wetlands. In D.D. Hook, W.H. McKee, Jr. H.K. Smith, J. Gregory, V.G. Burrell, Jr. M.R. DeVoe, R.E. Sojka, S. Gilbert, R. Banks, L.H. Stolzy, C. Brooks, T.D. Matthews, and T.H. Shear (Eds.), The Ecology and Management of Wetlands Volume 2: Management. Use and Value of Wetlands. Timber Press. Portland, Oregon, USA.

ARQUED, V.M. (1995): Ampliación del Estudio de recursos hidráulicos de la cuenca del Ebro, Confederación Hidrográfica del Ebro, Zaragoza. 
BEILFUSS, R.D. \& BARZEN, J.A. (1994): «Hydrological Wetland Restoration in the Mekong Delta, Vietnam». p. 453-468, In W.J. Mitsch (Ed.): Global Wetlands: Old World and New. Elsevier Science.

BREEDLOVE, B.W. \& DENNIS, W.M. (1983): «Wetland Reclamation: A Drainage Basin Approach». p. 90-99, In D.J. Robertson (Ed.), Reclamation and the Phosphate Industry. Proceedings of the Symposium of the Florida Institute of Phosphate Research, Bartow, Florida.

BOX, M. (1987): Humedales y áreas lacustres de la provincia de Alicante. Instituto de Estudios Juan Gil Albert - C.S.I.C., 290 pp.

CARTER, V. (1990): «Importance of Hydrologic Data for Interpreting Wetland Maps and Assessing Wetland Loss and Mitigation». p. 79-85, In U.S. Fish and Wildlife Service Biological Report 90 (18),

CASADO, S. \& MONTES C. (1995): Guía de los lagos y humedales de España. J.R.Reyero, Madrid. $154 \mathrm{pp}$.

CUSTODIO, E. (1995): El papel de la hidrología en los programas de restauración de humedales en ambientes fluctuantes. p. 43-60. In C. Montes, M. Oliver, J. Molina, and L. Cobos (Eds.). Bases ecológicas para la restauración de humedales en la cuenca mediterránea. Consejería de agricultura de la Junta de Andalucía, Sevilla.

DEL VALLE, J. (1993): «El régimen pluviométrico medio de la cuenca del río Jiloca», Geographicalia $30,145-154 \mathrm{pp}$.

DELER, P. (1990): Sistema de riegos de los siete pueblos del río Cella, Instituto de Estudios Turolenses, Inédito, Teruel.

DELER, P.P. (1995): La Fuente de Cella, P.P. Deler (Ed.), Cella.

FACI, J. \& MARTÍNEZ, A. (1991): Cálculo de la evapotranspiración de referencia en Aragón. D.G.A. Serie Estudios Agrarios.

FONT, I. (1988): Historia del clima de España, Instituto Nacional de Meteorología. Ministerio de transportes, turismo y comunicaciones, Madrid.

GARCÍA, L. \& JIMÉNEZ, J.M. (1985): Notas para la historia de la Meteorología en España. I.N.M. Madrid.

GARGAllO, A. J. (1996): El Concejo de Teruel en la Edad Media (1177-1327) Tomos I y II, Instituto de Estudios Turolenses, $841 \mathrm{pp}$, Teruel.

HERNÁNDEZ, A. et al. (1985): Mapa geológico de España a escala 1:200.000 (hoja 47, Teruel), primera edición, Instituto Geológico y Minero de España, Madrid.

MOLINA, F. (1995): Intervención en sistemas húmedos para su mantenimiento y/o restauración. p. 143-154. In C. Montes, M. Oliver, J. Molina, and L. Cobos (Eds.): Bases ecológicas para la restauración de humedales en la cuenca mediterránea, Consejería de agricultura de la Junta de Andalucía, Sevilla.

MONTES, C. (1990): Estudio de las Zonas Húmedas de la España Peninsular: Inventario y tipificación, Dirección General de Obras Hidráulicas, Ministerio de Obras Públicas y Urbanismo, Madrid.

PEÑA, J.L. et al. (2002): El Clima de la provincia de Teruel, Cartillas turolenses 20, Instituto de Estudios turolenses, Teruel.

RAMÍREZ, J.I. et al. (1983): Mapa geológico de España a escala 1:50.000 (hoja 541, Santa Eulalia), primera edición, Instituto Geológico y Minero de España, Madrid.

RUBIO, J. C. et al. (2003): Recuperación de humedales en el contexto de la nueva directiva Marco; Las lagunas del Cañizar (Provincia de Teruel). p. 97-102. In A.I.H. Grupo Español (Ed.): Presente y futuro del agua subterránea en España y la nueva Directiva Marco Europea, Instituto Geológico y Minero de España, Madrid.

RUBIO, J.C. (2002): Las lagunas perdidas del Alto Jiloca, Tirwal, Teruel.

RUBIO, J.C. (2004): Contexto hidrogeológico e histórico de los humedales del Cañizar. Publicaciones del Consejo de Protección de la Naturaleza de Aragón, Serie investigación, Zaragoza.

SALVAT, J. (1977): Climatología en la Edad media, VII Jornadas de la A.M.E., Madrid.

SAZ, M. A. (2003): Temperaturas y precipitaciones en la mitad Norte de España. Estudio dendroclimático. Publicaciones del Consejo de Protección de la Naturaleza de Aragón, Serie investigación, Zaragoza. 
SIMÓN, J.L. (1983): «Tectónica y neotectónica del sistema de fosas de Teruel». Revista Teruel 69, 21-97 pp.

TAI, C.C. \& FONG, C. (1995): «Hydrological Restoration of Wetlands by Hydraulic Modifications», p. 45-47. In M.C. Landin (Ed.): Proceedings of National Interagency Workshop on Wetlands: Technology Advances for Wetlands Science, April 3-7, New Orleans, Louisiana.

WHITE, J.M. \& BRAKE, L. A. (1995): «Description, History, and Water Chemistry of the Recently Restored Watervalley Wetlands in the Southeast of South Australia». Wetlands 15 (3), 247-257 pp.

WOLF. R.B. et al. (1986): «Wetland creation and restoration in the United States from 1970 to 1985: an annotated bibliography». Wetlands 6 (1), 1-88 pp. 
